\title{
Púrpura Trombocitopénico Idiopático (PTI) en Lactantes Menores de 4 meses
}

\author{
Dr. Marcial Osorio F.1-2; Dr. Pedro Advis V.3; Dra. Gabriela González C.2; \\ Dra. Rosa Díaz C. ${ }^{3}$; Dr. Manuel Olivares G. ${ }^{4}$

\section{Idiopathic Thombocytopenic Purpura (ITP)} \\ in Infants Less than 4 moths of age
}

\begin{abstract}
Seven cases of ITP in infants less than 4 months of age are described. The high prevalence of the diseasc in Chile and its appearence as epidemic sprouts is stressco. The alarming initial clinical picture, with purpura, splenomegaly, cpistaxis andior gastrointestinal bleeding, contrasts with the benign cyolution with clinical and laboratory normalization within 2 wecks. Some of the likcly ethiological factors of ITP in young infants were investigated. Serology for Cytomegalovirus (CMV), Rubella, Herpes simplex, Toxoplasma, Chagas and Lues was not compatible with present disease. Urine culture for CMV was negative. Other ethiological possibilities must be studied in order to explain this disease.
\end{abstract}

El término PTI define un estado hemorragiparo debido a una disminución del número de plaquetas circulantes, en ausencia de un trastorno sistémico asociado identificable y acompañado de normalidad de la médula ósea. ${ }^{1-8}$

Representa la forma más frecuente de trombocitopenia en la infancia, período en que tiene un curso agudo, seguido de recuperación espontánea en 70 a $90 \%$ de los casos. $1-8 \cdot 24$.

La máxima incidencia del PTI ocurre entre el $2^{\circ}$ y el $6^{\circ}$ año de vida ${ }^{-8}$. Parece que no existe en recién nacidos, en los que las trombocitope-

1 Trabajo de Ingeso a Ia Soc. Chilena de Pediatría. Presentado en el XIV Congreso Chileno Pediatría. Puerto Montt. 1982.

2 Depto. de Pediatría y Cirugía Infantil. División Ciencias Médicas Sur (Contral). Facultad de Mcdicina. Universidad de Chile.

${ }^{3}$ Servicio de Pediatría. Unidad de Hematología. Hospjtal Paula Jaraquemada.

4 Instituto de Nutrición y Tecnología de los Alimentos. División de Nutrición Humana y Ciencias Mćdicas. Unidad de Hematología. Universidad de Chile. nias son generalmente secundarias a causas identificables $9-10$. Las purpuras en lactantes menores representan el $4 \%$ del total en grandes series ${ }^{2 \cdot 3}$. En Chile, Ruiz Esquide $y$ Cols. ${ }^{12}$ y Campbell $y$ Cols. ${ }^{12}$ han descrito frecuencias de $14,5 \% \mathrm{y}$ $24,0 \%$ para este grupo de edad.

Esta mayor frecuencia coincide con lo observado por uno de los autores ${ }^{\mathbf{1}}$ y nos motivó a analizar las principales caracteristicas clinicas, acompañadas de un estudio etiológico, del púrpura en menores de 4 meses.

\section{MATERIAL Y METODOS}

Se realizó una evaluación prospectiva de los pacientes ingresados al Servicio de Pediatría del Hospital Paula Jaraquemada en el período comprendido entre Agosto de 1981 y Agosto de 1982 que cumplian los requisitos de tener Púrpura cutáneo; Disminución del recuento de plaquetas en sangre periférica $100 \mathrm{mil} . \mathrm{x} \mathrm{m^{3 }}$; Propor. ción de megacariocitos normal o aumentada en médula ósea; Ausencia de infección evidente, 
anomalias congénitas, ingestión de fármacos o patologías conocidas como causantes de trombocitopenia.

En los pacientes ingresados al estudio se descartó la presencia de infección por Cítomegalovi. rus (CMV), Herpes simplex, Rubeola, Toxoplasma, Chagas y Lúes, agentes descritos como causantes de trombocitopenia ${ }^{\text {4-16. }}$.

La evaluación de laboratorio incluyó Hematocrito, recuento de blancos y fórmula diferencial, recuento de plaquetas en frotis, mielograma, (mediante punción medular en tibia), tiempo de protrombina, tiempo de tromboplastina parcial activada, fibtinógeno, cultivos de orina para CMV ${ }^{3} 3$ reacción de fijación de complemento para CMV ${ }^{4}$ Toxoplasma y Chagas, inhibición de la hernaglutinación para virus Rubeola 15 VDRL.

\section{RESULTADOS}

En el período de un año, 18 pacientes cumplieron con los requisitos señalados para el diagnóstico de PTl. De ellos, 7 fueron lactantes menores de 4 meses.

Estos 7 lactantes eran eutróficos, recibían alimentación natural exclusiva y su desarrollo psicomotor era normal hasta el momento del ingreso.

En la Tabla 1, se muestra que la edad de ingreso de los 7 niños fluctuó entre 4 y 8 semanas de vida, 5 eran de sexo masculino. La enfermedad apareció predominante en invierno (5 casos), ocurriendo 4 en el mes de Agosto de 1981 .

Tabla 1 .

Antecedentes al Ingreso en Lactantes menores de $\mathbf{4}$ meses con PTI

$\begin{array}{lcccc}\begin{array}{c}\text { Caso } \\ \text { No }\end{array} & \begin{array}{c}\text { Edad } \\ \text { (semanas) }\end{array} & \text { Sexo } & \begin{array}{c}\text { Fecha } \\ \text { Ingreso }\end{array} & \begin{array}{c}\text { Coriza yjo } \\ \text { sintomas } \\ \text { bronquiales }\end{array} \\ 1 & 6 & \text { F } & \text { Agosto 81 } & - \\ 2 & 8 & \text { M } & \text { Agosto 81 } & + \\ 3 & 4 & \text { F } & \text { Agosto 81 } & + \\ 4 & 8 & \text { M } & \text { Agosto 81 } & + \\ 5 & 7 & \text { M } & \text { Diciem. 81 } & - \\ 6 & 7 & \text { M } & \text { Enero 82 } & + \\ 7 & 4 & \text { M } & \text { Agosto 82 } & -\end{array}$

En 4 lactantes se registraron antecedentes de coriza, síntomas bronquiales o ambos en las dos semanas previas al desarrollo del púrpura.

En la Tabla 2 se destacan las principales caracter ísticas del examen físico en el ingreso. En ella, se ve que en todos los lactantes había un púrpura extenso que comprometía cabeza, cue- llo, tronco, abdomen y extremidades, asociado a petequias del paladar y mucosa bucal. El comienzo de las manifestaciones purpúricas fue súbito, algunas horas antes de la admisión, y en seis casos se acompañí con epistaxis, melena, bazo palpable o ambos, presentándose el púrpura cutáneo como única manifestación en solo un caso. El aumento del tamaño del bazo fue moderado, sin características semiológicas que orientasen hacia un posible origen secundario del púrpura.

Tabla 2.

Características dci examen físico al ingres en lactances menores de 4 meses con PTI.

$\begin{array}{ccccc}\begin{array}{c}\text { Caso } \\ \text { No }\end{array} & \begin{array}{c}\text { Púrpura } \\ \text { Cutáneo }\end{array} & \text { Epistaxis } & \text { Mekena } & \begin{array}{c}\text { Bazo (cm. bajo } \\ \text { reborde costal). }\end{array} \\ 1 & + & + & + & 2 \\ 2 & + & + & - & 1 \\ 3 & + & + & + & - \\ 4 & + & + & + & - \\ 5 & + & - & - & - \\ 6 & + & - & - & 2 \\ 7 & + & - & - & 1\end{array}$

El recuento inicial de plaquetas fue menor de $4.000 \mathrm{x} \mathrm{mm}^{3}$ en los siete lactantes; en el mielograma la proporción de megacariocitos era normal o estaba aumentada. El hematocrito, fluctuó entre 26 y $32 \%$. El recuento de glóbulos blancos varió entre 4.500 y $12.000 \mathrm{x} \mathrm{mm}^{3}$, destacando el predominio de los linfocitos, algunos de ellos atípicos. Los tiempos de protrombina, tromboplastina parcial activada y el fibrinógeno fueron normales en los cuatro casos investigados. Los exámenes destinados a descartar infección por CMV, Herpes simplex, Rubeola, Toxoplasmosis, Chagas y Lúes mediante serología no fueron compatibles con enfermedad actual en las madres, ni en los lactantes con PTI. Los cultivos de orina para CMV resultason negativos.

Tres de los siete pacientes recibieron Prednisona $2 \mathrm{mg} / \mathrm{kg} / \mathrm{dia}$ durante 15 dias.

La disminución del púrpura comenzó hacia el tercer o cuarto día, desapareciendo alrededor del décimo. El bazo involucionó en forma más o menos simultánea. No apreciamos diferencias en la evolución de los pacientes que recibieron tratamiento esteroidal respecto de los que no lo recibieron.

Un año después de su egreso, estos pacientes permanecían asintomáticos y sin hepatoesplenomegalia.

\section{DISCUSION}

La incidencia máxima del PTI ocurre en los periodos de preescolar y escolar ${ }^{1 \cdot 8 \cdot 24}$ correspon- 
diendo, según la literatura extranjera a los lactantes menores solo 1 a $4 \%$ de los casos ${ }^{2-3}$. En Chile la frecuencia del PTI en lactantes menores parece ser mayor de acuerdo a investigaciones de Ruiz Esquide y Cols. $(14,5 \%)^{11}$ y Campbell y Cols. $(24 \%)^{12}$.

En nuestra evaluación de lo sucedido en un año en el Servicio de Pediatría del Hospital Paula Jaraquemada, los lactantes menores de 4 meses representán el $40 \%$ del total de los púrpuras. Este elevado porcentaje puede estar deformado por la tendencia de la enfermedad a aparecer en brotes en este grupo etario ${ }^{1-12}$ lo que se ve reafirmado por la aparición de 4 de los siete casos en el mes de Agosto de 1981.

El PTl de la infancia afecta a ambos sexos con igual frecuencia ${ }^{1-8}$ el predominio en varones observados en nuestros siete pacientes es de valor limitado por lo reducido del número de casos.

Se describe que en el PTI es frecuente el antecedente de enfermedad viral precediendo en una a seis semanas, la aparición del cuadro hemorragiparo ${ }^{-\beta}$. En nuestros niños existió este antecedente en cuatro de los siete casos.

Clínicamente la manifestación hemorrágica se describe como variable desde alguna equímosis en relación a traumatismos, hasta un púrpura florido que compromete tronco, abdomen, pelvis y extremidades, asociado con petequias del paladar, mucosa bucal y hemorragias subconjuntivales ${ }^{1-6-8}$ como ocurrió en nuestros pacientes. Es habituaj la asociación a epistaxis ${ }^{1-6-8}$ coinciden. te con nuestros hallazgos y que difiere de lo encontrado en lactantes menores por Ruiz Esquide y Cols. y Campbell y Cols, en que es una manifestación infrecuente. La hemorragia gastro. intestinal se describe como una manifestación alarmante, pero de escasa frecuencia ${ }^{1-6 \cdot 8}$. Este punto es tal vez el de mayor divergencia en cuadro clínico de los lactantes menores de 4 meses respecto a los niños mayores, ya que en los lactantes menores la hemorragia digestiva constituye una manifestación frecuente ${ }^{1-12}$ (3/7 de nuestros casos). lgualmente es mayor en estos pequeños pacientes, la frecuencia con que se logra palpar el bazo, la que en niños mayores no difiere de la población normal ${ }^{6-7}$ y cuyo hallazgo obliga a estudiar causas secundarias del púrpura, como pueden ser la leucemia, mononucleosis infecciosa o el lupus eritematoso diseminado ${ }^{8}$.

El laboratorio coincide con lo descrito clásica mente $^{1-\theta}$ : recuento de plaquetas, menos de $40.000 \times \mathrm{mm}^{3}$. El mielograma, fundamental para descartar otras causas de trombocitopenia, reveló proporción de megacariocitos normal o aumentada en médula ósea.

Las cifras del recuento de blancos estuvieron dentro de lo normal con predominio de linfocitos $y$ aparición de formas at ípicas.

La presencia de anemia se describe como poco frecuente $^{\mathbf{l}-7}$; en este grupo de lactantes menores el ricsgo de tenerla es mayor, y la evaluación de ella es más dificil, por encontrarse alrededor de la edad de máxima intensidad de la anemia "fisiológica".

Las pruebas de coagulación realizadas en cuatro casos fueron normales, como se describe clásicamente. 1-7-8

Si bien el uso de corticoides en el PTI del niño es motivo de controversias ${ }^{3-5.7}$ tres de nuestros pacientes recibiecon Prednisona $2 \mathrm{mg}$. $\mathrm{kg}$ día durante 15 días, dada la intensidad inicial de las manifestaciones hemorragiparas, ya que, si bien el riesgo de hemorragia del sistema nervioso es menor de $1 \%$, aún existe ${ }^{3}$.

El PTI agudo se recupera en un período que varia de 304 días a 6 meses ${ }^{1-8}$. En nuestros pacientes esto ocurrió antes de 3 semanas del inicio del cuadro. sin que apreciásemos diferencias clínicas entre los niños que recibieton corticoides y los que no to hicieron.

En adultos se ha demostrado el origen inmune de la enfermedad, con formación de autoanticuerpos que se unen a las plaquetas que luego son removidas de la circulación por el bazo y otros órganos del sistema reticulo endotelial ${ }^{25-27}$. En los niños se ha demostrado estos anticuerpos en el 12 a $88 \%$ de los $\operatorname{casos}^{2}$. En nuestros casos no se realizaron esos estudios.

La infección también puede producje trombocitopenia ${ }^{1-7-24}$ siendo una causa frecuente de ella en el recién nacido ${ }^{10}$. Por la edad de nuestros pacientes se investigó la posibilidad de infección por los agentes más frecuentemente involucrados como causas de trombocitopenia, con el fin de evitar incluir erróneamente entre los PTI casos de etiología identificada. Se realizaron cultivos de orina para CMV e investigación serológica con técnica de fijación de complemento para CMV Toxoplasma, Chagas y Herpes simplex, e Inhibición de la Hemaglutinación para virus $\mathbf{R u}$ beola, además de VDRL en todos los casos. La ausencia de manifestaciones clínicas compatibles con enfermedad ${ }^{17.22}$ por estos agentes, así como la negatividad de las investigaciones realizadas creemos nos permiten destacarlos como agentes etiológicos en nuestros pacientes.

Taboada aisló CMV en algunos casos de púrpura en lactantes menores, y propuso un probable rol causal de este virus ${ }^{23}$. Si bien esto no se puede descartar, el virus parece no tener un papel predominante en la etiología del PTI en lactantes menores, de acuerdo a nuestros resultados y los de Ruiz Esquide y Cols, quienes tampoco demostraron la presencia del agente en sus casos. 
La presencia de sintomas respiratorios antes del púrpura en un alto porcentaje de los casos en lactantes menores, ${ }^{1-12}$ coincide con nuestros hallazgos y nos hace suponer, un posible origen inmunológico del cuadro, semejante al que parece ocurrir en el PTI de pre-escolar y escolares $^{7 \cdot 25-27}$

En conclusión, el PTI del lactante menor de tres o cuatro meses parece tener en Chile una frecuencia mayor a la descrita en forma habitual en otros países presentándose en pequeños brotes epidémicos, y difiriendo del que ocurre en niños mayores, en la mayor frecuencia de hemorragia digestiva y bazo palpable en una edad en que la anemia "fisiológica" alcanza su mayor intensidad, lo que da al cuadro un aspecto clínico inicial alarmante. Su mecanismo de producción no está claro y abre un campo de investigación que ayude a aclarar el origen del trastorno, cuyo estudio se recomienda enfocar como en los púrpuras neonatales ${ }^{1-2 \cdot 3}$.

\section{RESUMEN}

Se estudiaron 7 casos de PTl en lactantes menores de 4 meses. Se destaca su alta frecuencia en nuestro Pais, con distribución en pequeños brotes epidérnicos, sindrome clínico inicial alarmante por la intensidad de las manifestaciones hemorragíparas de piel $y$ mucosas, pero de evolución muy benigna, acompañada de normalización clínica y de laboratorio en 2 o 3 semanas desde el inicio de la enfermedad.

El estudio de las causas más probables en menores de 4 meses, utilizando serología para Citomegalovirus, Rubeola, Herpes simplex, Toxoplasma, Chagas, Lúes y cultivos de orina para Citomegalovirus resultó no compatible con enfer. medad actual por estos agentes en los 7 casos.

Se sugiere continuar el estudio de otras posibilidades etiológicas del trastorno.

\section{AGRADECIMIENTOS}

A la sección virologia del Institu to de Salud Pública, donde se realizaron los exámenes para CMV, Herpes Simplex y Rubeola.

\section{REFERENCIAS}

I Stuar, M.J. and Mackenna, R.: Childhood idiopathic thrombocytopenic purpura, in Nathan David G. and Oski Frank A. Hematology of Infancy and Childhood 1981, WB. Saunders Co. Philadelphia.

2 Lusher F.M. and Zueizer WW.: ldiopathic Thrombocytopenic purpura in Childood J. Pediatr. 68: 971 , 1966.

${ }^{3}$ Lammi A.T. and Lowic V.A.: Idiopathic thrombocytopenic purpura: An epidemiology studio. J. Pediatr. 83: 31,1973

${ }^{4}$ Simons S.M.: Main Ch. A.: Yaish H.M. and Rutzby J. Idiopathic thrombocy topenic purpura in children J. Pediatr. 87: 16, 1975 .
5 Wc. Clure P.D.: Idiopathic thrombocy topenic PurpuIa in children. Diagnosis and management. Pediatrics $55: 68,1975$,

6 Af Willioms NB and Maurer H.M.: Acute Idiopathic thrombocytopenic Purpura in children. Am. J. Hematol. 7: 87, 1979.

7 Andrew Matreen and Barr Ronald.: Incteased Platelet Destruction in infancy and Childhood. Semin. Thromb. Hemostas 8: 248, 1982.

s Burnstein $Y$, and Berms L.: Acquired Inmmune Thrombocytopenic Purpura (ITP) in childhood. Pediatric Annals 11: 323, 1982.

9 Anthony B. and Krivit $W .:$ Neonatal thrombocy to penic purpura. Pediatrics 30:.776, 1962.

10 Oski Fa and Naimon J.L.: Hematologic problems in the Newborn, ed. 2 Philadelphia, 1972, WB Saunders Company.

11 Ruiz-Esquide F., Vargas L., Pino R.: Púrpura trombocitopénica primaria en el lactante menor de 3 meses. Bol. Med. Hosp. lnfant. Mex. 36: 621, 1979.

12 Campbell, M,; Araniz P.; Taboada H.; Púrpura trombocitopénico "Ldiopático" en lactantes mentores de 3 meses. Infección perinatal por citomegalovirus. Rev. Chil. Pediat. 50: 7, 1979.

13 Advis, P.: Comunicación personal.

14 Lenerte $E$. and Schmidt N.: Diagnostic Procedure for viral and Rickettsial infections. ed. 4, 1969. American Public, Health Association.

Is Sever J.L.: Application of microtechnique to viral serological investigations. J. Inmunol. 83; 320, 1962.

16 Center for Disease Control CDC: : Standard Rubella Hemagglutination Test. 1970.

17 Weller T.H. The cytomegaloviruses: Ubiquitous agents witl protean clinical manifestacions. N. Eng. J. Med. 285: 203 and 267, 1971.

18 Starr J,G. Bart R, and Gold E.: Inapparent Congenital Cytomegalovirus Infection Clinical and Epidemiologic Characteristics in Early knfany N. Engl. J. Med. 282: 1075, 1970.

19 Lukens I.N.: Neonatal Haematological Abnormalities Assocíated with Matecnal Discase. Clin. Haematol. 7: 155, 1978.

${ }^{20}$ Cooper, L.i Neonatal thrombocytopenic Purpura and other manifestations of Rubella contracted in Utero. Am. J. Dis. Child. 110:416, 1965.

21 Whitley, R.J. Nohmias $A J$, Visontine AM. Fleming $C t$. and Alford $\mathrm{Ca}$ : The natural history of herpes simplex virus infection of mother and newborn, Pcdiatrics. $66: 489,1980$.

22 Aklfors K., Ivarsson SA., Johnsson $r$, and Svensson I.: Congenital and Acquired Cytomegalovirus Infections. Acta Paediatr. Scand. 67: 321, 1978.

23 Taboada, H., Campbell, M., Osses, M. Pruyeras M. Vergara M.I.: Púrpura trombocitopénica del lactante menor causada por la infección perinatal por citomegalovirus. Bol. Med. Hosp. Infant. Mex, 36: 743, 1979.

24 Lightsey LA.: Thrombocytopenia in Children. Pediatr. Clin. North Am. 27: 293, 1980.

25 Lightsey LA. HM Koenig. R. MC Millan, IR Stone.: Plateletassociated inmunoglobulin $G$ in childhood idiopathic thrombocytopenic purpura. J. Pediatr. 94: 201, 1979 .

${ }^{26}$ Mc Intosh S., C. Johnson, P. Hartigan, A. Baumgarten, J.M. Dwyer: Immunoregalatory abnormaljties in children with thrombocytopenic purpura $J$. Pediatr. 99: 525, 1981.

27 Tomar R.H. and Stuard MJ: Predicting acute vs chronic childhood idiopathic thrombocytopenic purpura. Am. J. Dis. Child. 135: 446, 1981. 